\title{
Pd-Catalyzed Aldol Reaction for Formation of Chiral Quaternary Centers
}

Metal-Catalyzed Asymmetric Synthesis and Stereoselective

Reactions

\section{Key words}

palladium

quaternary centers

catalytic aldol reaction<smiles>CCOC1(C(O)/C=C/c2ccccc2)CCCCC1=O</smiles>

$43-86 \%$ yield $\mathrm{dr}=2: 1$ to $6: 1$ $96-99 \%$ ee

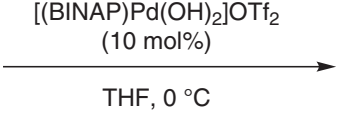

2

(1.5-4 equiv)

Selected examples:<smiles>CCOC(/C=C/c1ccccc1)C1CCCCC1=O</smiles>

$3 a$

$85 \%(d r=5: 1)$ $99 \%$ ee $(95 \%$ ee $)$<smiles>CCCCOC(C=CP)C1CCCCC1=O</smiles>

$3 \mathbf{b}$

$$
71 \%(\mathrm{dr}=5: 1)
$$
$99 \%$ ee $(99 \%$ ee)<smiles>C=CCOC(C=Cc1ccccc1)C1CCCC1=O</smiles>
$3 \mathbf{3 c}$ $99 \%$ ee $(98 \%$ ee)<smiles>C=CCOC(C=Cc1ccccc1)C(C)C(C)=O</smiles><smiles>[131In]</smiles>
$41 \%(\mathrm{dr}=4.5: 1) \quad$ with [(Tol-BINAP)Pt(OTf $\left.)_{2}\right]$ $99 \%$ ee (n.d.) $\quad 71 \%(\mathrm{dr}=2.5: 1)$ $97 \%$ ee $(96 \%$ ee)

$$
\overbrace{\mathrm{Me}}^{O \mathrm{Bn}}
$$

\section{$3 e$}<smiles>CCOC(C)C1CCCCC1=O</smiles>

$50 \%(\mathrm{dr}=2: 1)$ $99 \%$ ee (n.d.)

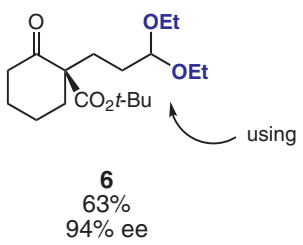

5 $99 \%$ ee $(99 \%$ ee)
Significance: The low nucleophilicity of 1,3-dicarbonyl metal enolates and the ready retro-aldol reaction have stalled the development of metal catalysts for asymmetric aldol reactions. The protocol uses overall neutral conditions where only the metal center acts as Lewis acid. Using BINAP as the chiral ligand, the reaction yields protected alcohols directly with excellent enantioselectivity.
Comment: Recognizing acetals as oxocarbenium ion precursors is the key for the success of the reaction. Competitive retro-aldol reactions are prevented. Furthermore, the strategy affords highly functionalized chiral products bearing chemodifferented synthetic handles (ketone, alkene, ester and protected alcohol). In some cases, a palladium catalyst was not optimal and necessitated the use of a more stable platinum catalyst (i.e. 3e). Intriguingly, when an unsubstituted acrylate acetal was used, it reacted via a 1,4-addition (6). 